\title{
Conceptualization and Integration of Information Systems in Educational Business Activities
}

\author{
Salah Alkhafaji \\ Associate Prof, IST Department, Sur University College, PO: 440, PC: 411, Sur, \\ Sultanate of Oman \\ E-mail: dr_salahalkhafaji@yahoo.co.uk, Tel: +968-92626890, Tel : +968-25546691 \\ B. Sriram \\ Quality Assurance Officer and Lecturer, IST Department, Sur University College, PO: 440, PC: 411, Sur, Sultanate of \\ Oman \\ Email: srishan11@gmail.com, sriram@suc.edu.om, Tel: +968-92186725
}

\begin{abstract}
The business activities are highly incorporated with the technology development and need to be updated periodically. Business activities have made the technology to be more creative and innovative. The organizations need to integrate their business activities into a single system to achieve their aims and objectives successfully. Various studies are already conducted in integrating such business activities as Business Process Management System. In particular, various management systems are available in the market to integrate the educational business processes. The educational business processes are changing due to the various international bench markings. The educational business processes perspectives could not be met exactly to the requirements in some of the available software. As the currently available systems suits to some of the educational institutions in particular region of the world, there are needs to review them to the current requirements. This paper identifies the gaps between the current potential educational requirements and availability of educational business processes management systems. The major impact factors of the educational processes are identified and based on the findings a model has been proposed.
\end{abstract}

Index Terms - Harmonic Integration, Business Intelligence Systems, Business Process Management System, Educational Business Activities.

Note: This is fully revised and updated version of: Dr. Salah Alkhafaji, Sriram.B - "Harmonic Integration of Information Systems in Business Processes" - Accepted for First International Conference on Information Technology - College of Applied Science, Sur, Oman to be scheduled.

\section{INTRODUCTION}

\subsection{General Introduction}

The technological development helps in each and every activities of the business either directly or indirectly. The organizations are made to link their business processes using various business process management systems available based on the requirements. The enterprise resource planning tools help to conduct the business activities smoothly and effectively. All the business activities need to be integrated for efficient performances. The set of interrelated activities performed by various departments and units of the business require proper integration for harmonic conduction of the business activities.

The modern technology has transformed the business processes into various higher degrees to compete and exist in the business. Every business requires various inputs from internal and external units and manipulates the same for day to-day activities. The different levels of the organization need the information regarding its business activities in time to work cost effectively. In education field, there are various activities that have to be linked properly in order to maintain quality in all activities. The fundamental principle of such integration of activities is to enable free flow of information.

Managing such business activities through proper information system has nevertheless vital role in business successes. The information technology helps the organizations to apply the various management techniques to achieve the mission and vision. Managing business processes need critical evaluation on available systems for proper integration. Apart from that, there is a need to integrate all business processes into a single information system and to be economical and feasible.

Various studies were conducted to integrate the business processes in single system as business process management systems. The core idea of this paper is to elicit the major business activities of an educational institution that have to be integrated in order to run the business smoothly. Also, this paper identifies the gaps between the educational requirements and the currently available business process management systems. The factors that influences the day - to - day educational business activities are identified and a model has been proposed considering the business processes of a higher education institution.

The current problems in the existing systems were identified and the corresponding objectives and 
hypotheses were set. The previous studies on this topic were referred under literature review. The research methodology has been identified and the findings were summarized with respect to various perspectives of the systems. Finally we have proposed a model for the applications.

\subsection{Statement of Problem}

Though most of the currently available business process management systems have the necessary techniques to integrate the various business processes into one system, still they are not sufficient in some cases. As the educational processes depend on the nature and type of the institution, the business processes in education do not follow the same activities that are available in the current systems. The issue is to integrate these processes harmonically into single system which will be useful for any educational institutions. The business activities are influenced by various factors, in turn, the whole system.

\subsection{Objectives and Hypotheses}

Objective 1: To identify the factors that affects the educational business processes

Hypothesis 1: The major factors that affect the educational business processes are: Students and Student Support Activities, Staff and Staff Support Activities, Financial Activities, and Academic Learning Processes.

Objective 2: To identify the business process management system potentials and the educational business activities requirements

Hypothesis 2: The currently available business processes management systems address all the requirements of the educational activities

Objective 3: To identify the methodologies to harmonically integrate the educational business processes into single system

Hypothesis 3: The educational processes shall be harmonically integrated into single system with maximum efficiencies by using currently available widgets and tools

Objective 4: To identify the gaps between the currently available business process management systems and educational require ments

Hypothesis 4: There is no gap in the currently available business processes management systems and the educational requirements

\section{LITERATURE REVIEW}

Dan et al (2010) identified that the business processes must be agile. This will help the processes to respond to the changes in the environment. Event Driven business process management is an enhancement of business process management ${ }^{[1]}$

Cale and Kanter (1998) clearly stated that a major concern of senior information technology executives is achieving alignment between the technology and strategic interest of the overall organization ${ }^{[2]}$.

Henderson and Venketraman (1993) said, though Information technology has evolved from the administrative support toward more strategic role within an organization, still there are lacking in fundamental frame works for the future of the organization ${ }^{[3]}$.

Apart from that as Hollander et al (2000) suggested the information risks in the business activities need to be considered. The organizations must develop and implement a system of controls to manage such risks. The most important issue of translating strategic objectives into effective business process design is challenging. The lack of a clear definition of business processes has been the principal cause of a longstanding disconnect between strategy formulation and implementation. ${ }^{[4] \text {. }}$

As Kalpan et al (2008) said the companies are made to trim their bottom line activities due to rapid dot-com boom. The business sector has when IT and business executives jointly take an end to end look at business processes to cut the cost. In every organization the management processes depend on the business processes. The changes in the management processes and business processes affect the information processes. Thus, an organizations business processes, management processes and information processes need to be integrated for achieving the overall organization's objectives. ${ }^{[5]}$

As Sandoe et al (2001) said, to get the optimal benefits out of the integrated enterprise systems, the current business models and processes require significant changes. Computing has to be viewed from specialized tools to organizational resources. The organization has to allocate them most appropriately within the organizational setting ${ }^{[6]}$.

Vom Brocke et al (2010) discussed that the business process management has emerged as a popular management approach in information systems and business practices. Business process management has been given top priority during last decade. As they said, Business Process Management is mostly employed to improve, re-design or re-engineer existing business operations so as to improve overall effectiveness or efficiency of an enterprise. ${ }^{\text {[7] }}$

Zott, Amit, Massa (2010) said that the burgeoning literature on business models is young. A common conceptual base is still lacking. According to their point of views the business models should be considered as the activity system ${ }^{[8]}$.

\section{RESEA RCH METHODOLOGY}

The research has been conducted by analyzing the secondary data and analyzing the available software. To identify the potential requirements of educational activities, various educational business activities were observed and studied. The different frameworks defined by the accreditation authorities and government agencies were studied for identifying the major impact factors of the business processes. Interviews were conducted with 
the staff members working in various departments. Currently available some software's were studied for their available features and supports. Some available systems were analyzed for their performances. The student's activities in class rooms, labs and examination were observed to identify the potential requirements. The instructors were also observed for the teaching, assessment requirements during their teaching.

As suggested by Sommerville (2007), the available software was tested for maintainability, dependability, efficiency and usability which are considered as the essential attributes of a good software ${ }^{[9]}$. The functional and non functional emergent properties of the systems were analyzed critically to understand the interdependent components. The reliability, safety and security of the available systems were tested for operational performances. The designing of the system has to be designed by proper design space analysis described by Allan Dix et al (2008). ${ }^{[10]}$

\section{FINDINGS}

The information technology developments have made the business activities easy and creative. The previous studies on integrating educational business activities proved that the business process management system. The educational business requirements depend on the type and size of the higher education institute. A college with less number of students shall manage and integrate their activities with simple campus management systems and business process management systems. But, a higher education provider with more number of courses, more number of students and various other activities need specially designed system to meet their requirements. They need to integrate all their activities in order to meet their goal and objectives.

The following activities were identified as the important factors that affect the educational processes. They are: Students and student's related activities, Staff and Staff Support activities, Financial Related activities and Other Support Activities. Most of the currently available business processes management addresses the requirements of the educational activities. But some do not match to the individual requirements of the institutions. Some software found that they harmonically integrate the educational business processes into single system. But, it has been observed that some systems lack in efficiency, effectiveness, and regional requirements.

\subsection{Students and Student's related business activities}

In educational processes students are the main entities who are related to all the other activities. The system should have Student Personal Records as one of the main entity. The business process management system should provide proper tools and gadgets to collect required information regarding the students including their personal information for record maintenance. The student's photo should also be uploaded in the profile.
Most of the currently available systems provide such facilities. The other major activities such as certificate management, mark sheet management, attendance management and document management should be ma intained under "Student Support Activities".

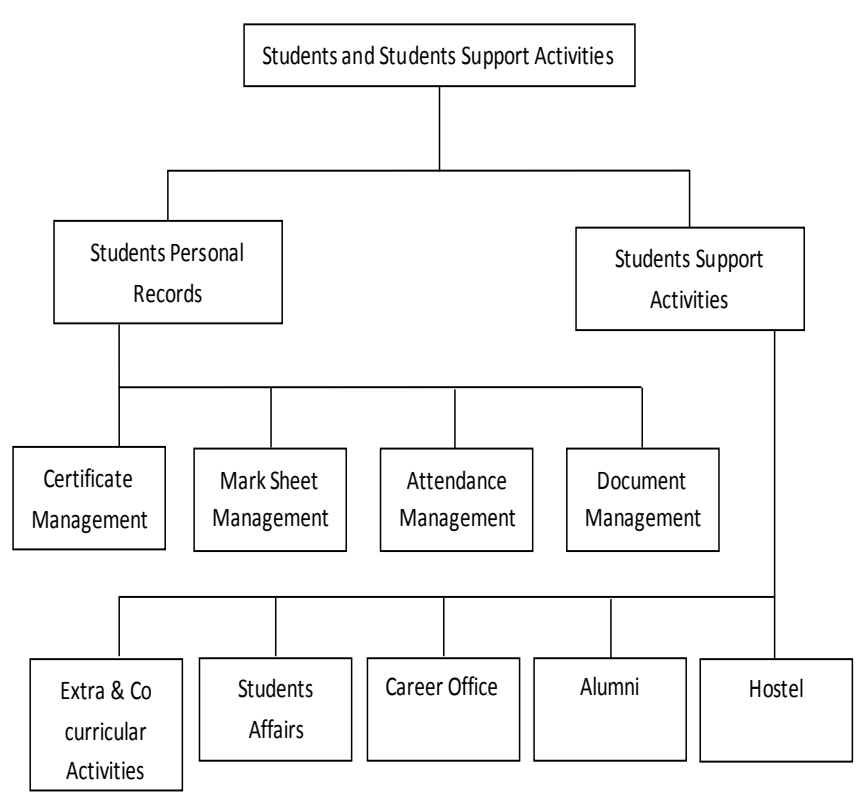

Figure 1: Business Processes hierarchy with respect to students

The "Hostel Administration", Alumni Association Management System", "Career Office” and other student support activities such as "Students Affairs Management" should be maintained under this activity. Some institutions may not have hostel facilities. Based on the institution type and requirements the activities may be added or deleted. But based on the quality assurance requirements, alumni association and career office are most important entities of the system. The activities such as students co-curricular and extracurricular activities shall be considered in students' affairs management section. Fig 1 depicts the activities related to this business activity.

\subsection{Staff and Staff Support Activities}

The second major entity of the system is all type of staffs. The staff members play the second major role in the system. Based on the performances of the staff, the number of students increases every year. The "Staff Personal Information System" should contain all the details of the staff members. Their qualification, nature of appointment, salary and other benefits should be clearly updated to this system. The increments and other allowance should be clearly mentioned in the database so as to generate the expenses reports and budgets. The type (academic, administrative, support), nature (full time, part time) and rank will help to generate the required reports as and when required. Fig 2 shows the staff and staff related activities. 


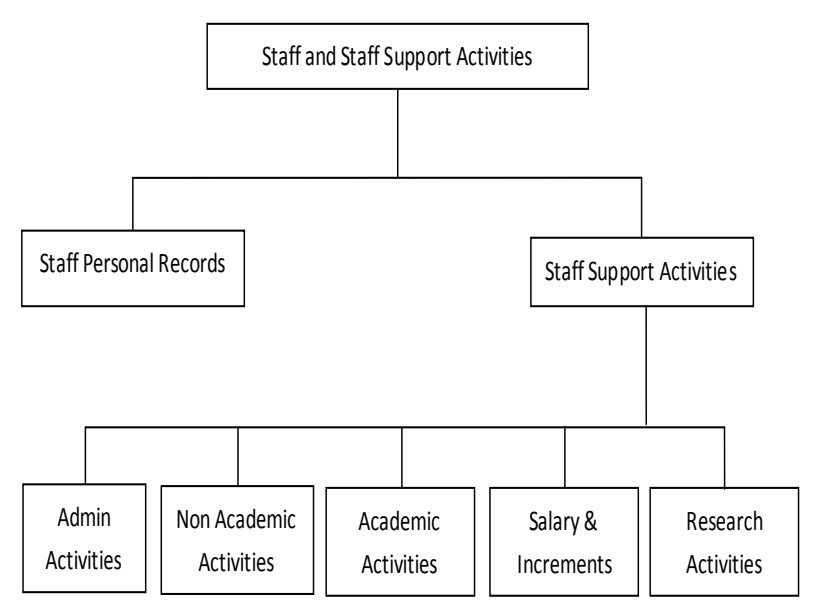

Figure 2: Staff Support Business Processes

\subsection{Financial Activities}

The financial activities such as fees collection and management, payroll management system and other income and expenses system should be maintained properly under this activity. This is the major activity that is linked to all the services of the higher education. The income and expenditure account related to each and every area of the higher education business process should be maintained in order to fulfill the mission and vision statements. There should be explicit link between the financial provisions, budgets to the strategic action plans of the higher education provider.

The "Fees Collection \& Management" is the most important factor that affects the whole educational activities, in particular, in private higher education providers. The fees generation is the major issue that to be addressed in the system. The student's particular regarding their mode of study, fees payment, discounts if any should be maintained properly. As the discounts differ for each student, it has been observed that the finance department faces problems in fees generation. The higher education institutions aims and objectives shall be met only on proper fees generation and collection. The student's fees play the vital role in meeting the budget and other expenses. Thus, the proper fees generation system should be implemented in the system. The fees management system should have the proper queries and reports in such a way that they can be formulated and printed at any point of time.

The staff personal information should be linked to "Payroll Management System" of the financial activities. The staff salary shall be generated at the end of every month and approved digitally. The allowances for the staff's other activities such as research and consultation, field trips and other staff development activities shall be updated manually every month based on their performance. This will help the financial admin istration department by all means. The time and work will be reduced considerably. Fig 3 reflects the Financial Activities involved in the educational business processes.
These financial activities vary based on the size and type of the institution. The institution with more academic and support activities may have more financial activities.

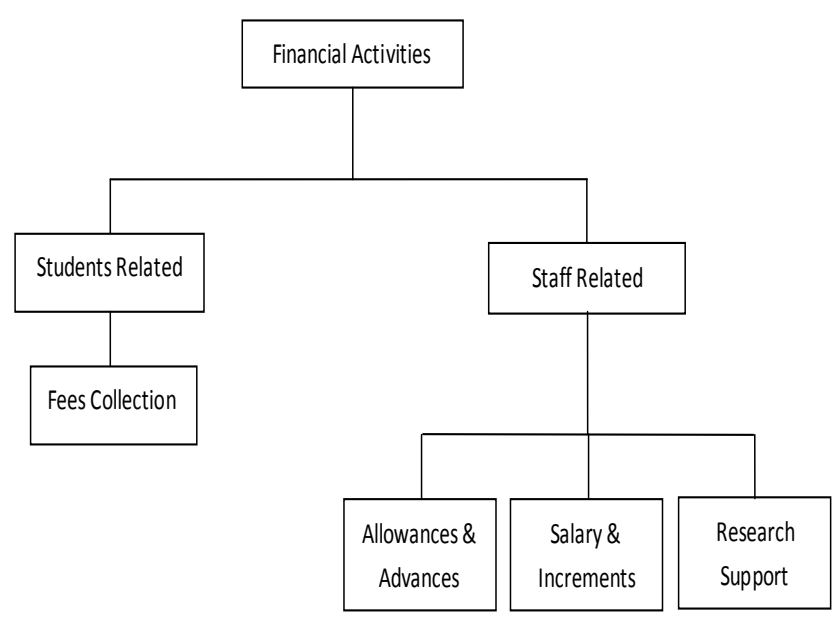

Figure 3: Major Financial Activities

\subsection{Academic Learning Process}

The "Course Administration System" should have the details of the courses selected by the students at each level and each semester. This system should contain the course code, course name, credit hours, practical session, prerequisite, course level and course major. This should be interrelated to the "Timetable Scheduling System" of other activities. Based on the expected number of students to register for the particular semester, the courses should be automated with the help of timetable scheduling system. The activities such as "Classroom Management System”, “Lab Management Systems” shall be maintained under this academic learning. Fig 4 shows the major activities under this area.

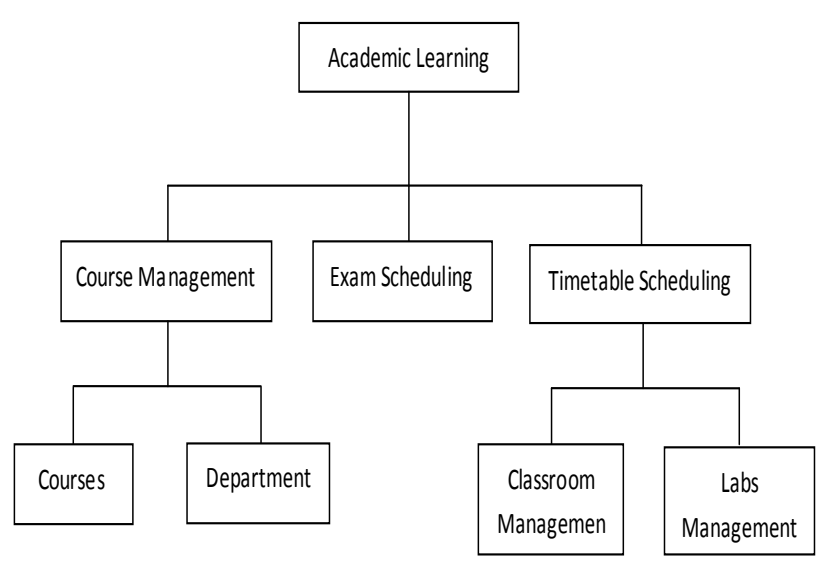

Figure 4: Academic Learning Related Business Processes

\subsection{Other Activities}

The other activities such as "Quality Assurance Management System”, Inventory, Building and Provisions Management System, Library Management Systems shall be maintained under this activity system. 


\section{PROPOSED MODEL}

The following model has been proposed based on the findings. We have defined a model by considering business processes of a higher education provider in general for integrating such business processes into a single affordable information system.

Activity Diagram of the Model:

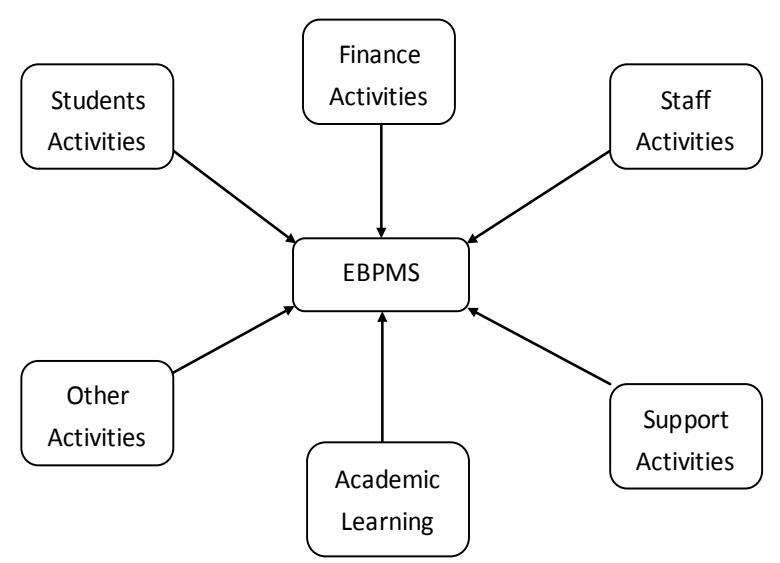

Figure 5: Activity Diagram of the Model

\section{CONCLUSION}

Thus Information technology development has made the business processes more stable and creative. In particular, educational business activities have been developed enormously. Due to increasing business challenges, the business key people have been stimulated to innovate new business strategies to manage business activities effectively and efficiently. Current business process approaches and models define enterprise activities with respect to potential applications. The business organizations select their business process systems based on their strategic aims, objectives and the nature of the business.

Managing such business activities through proper information system has nevertheless vital role in business successes. The information technology has tremendous growth in past decades and continually improving and changing drastically. In this situation, managing business processes need critical evaluation on available systems for proper integration. Apart from that, there is a need to integrate all business processes into an enterprise application system "a single information system” to achieve their goals success fully.

\section{ACKNOW LEDGEMENT}

We would like to thank Sur University College Management for their financial and moral supports for completing this research. We would also like to thank the dean of Sur University College for his extensive supports in conducting the research activities in the institution.

\section{REFERENCES}

[1]. Dan, F. Gittler, and F. Toumani (Eds.): ICSOC/ServiceWave 2009, LNCS 6275, pp. 370384, 2010. (C) Springer-Verlag Berlin Heidelberg 2010.

[2]. Cale, E.G., Kanter, J., (1998) - “Aligning Information Systems and Business Strategy: A Case Study" - Journal of Information Technology Management - Vol IX, Number 1.

[3]. Henderson, J.C., Venketraman, N., (1999) Strategic Alignment: Leveraging Information Technology for Transforming Organization - IBM System Journal, Vol 36, No 2 \& 3. DOI:10.1147/sj.321.0002.

[4]. Hollander, A.S., Denna, E.L., Cherrington, J.O., (2000) - Accounting, Information Technology and Business Solutions - 2e - Irwin McGraw Hill ISBN: 0071164545.

[5]. Kalpan., J.M., Roberts, R.P., Sikes, J., (2008) "Managing IT in a Downturn: Beyond Cost Cutting” - The Mckinsey Quarterly - Vis ited and retrieved from.

[6]. http://www.mckinseyquarterly.com/article_print.asp $\mathrm{x}$ ? L2=13\&L3=13\&ar=2196.

[7]. Sandoe, K., Corbitt, G., Boykin, R., (2001) Enterprise Integration - John Wiley \& Sons - ISBN: 0471359939.

[8]. Vom Brocke, Jan and Recker, Jan C. and Mendling, Jan (2010) Value-oriented process modeling : integrating financial perspectives into business process redesign. Business Process Management Journal, 16(2). pp. 333-356. Copyright 2010 Emerald. DOI:10.1108/14637151011035633.

[9]. Zott, C., Amit, R., Massa, L., (2010) - “The Business Model: Theoretical Roots, Recent Developments and Future Research” - Working paper WP - 862 - IESE Business School.

[10]. Sommerville - Software Engineering - 8e (2009) - Pearson Education.

[11]. Alan Dix, Janet Finlay, Abowd, G.D., Beale, R. (2008) - Human Computer Interaction - 3 e Pears on Education - ISBN: $81-317-1703-8$

[12]. Academia ERP - Campus Management System Serosoft, www.academiaerp.com.

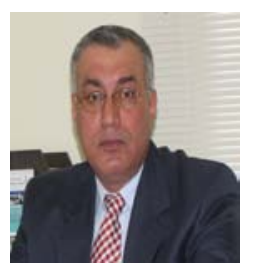

Dr. Salah Alkhafaji - Associate Professor Dr. Salah Alkafaji, working for Sur University holds Bachelor degree in Computer Control Engineering from the University of Technology (Iraq) 1984, Master degree in Computer Engineering from London College-Kensington University College (UK) 1999, and Ph.D degree in 
Management Information Systems from London College-Kensington University College (UK) 2003.

Dr. Alkhafaji held several academic and admin istration positions: Computer Control and Systems Senior Engineer for (8) years in the Military Industries Corporations (Iraq), IT manager for more than (6) years in the Military Industries Corporations (Iraq), He worked as Assistant Dean for Students' Affairs and Admin istrative Affairs - SUC since (August 2008), chair person of Information and technology department - SUC for more than (3) years, and More than 20 years of teaching experience in several universities. He is a member in different professional societies: Iraqi Engineering Association (IEA), Iraqi Eng ineering Union (IEU), and Iraqi Computer Association (ICA). Dr. Alkhafaji presented more than (14) papers in conferences and seminars, Published (8) research papers, (2) handbooks, and (3) articles in journals, and $\mathrm{He}$ developed a software system for educational hypermedia

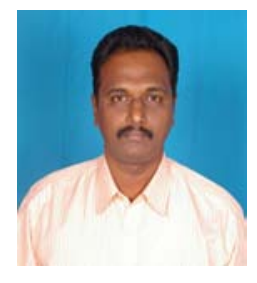

B. Sriram - is working for Sur University College, Sultanate of Oman as Lecturer since 2004 and Quality Assurance Officer since 2009. He has 20 years of teaching experience in Mathematics and IT subjects. He has published 14 research papers in peer reviewed national and international journals and presented 10 papers in national and international symposiums.

He is an active researcher in his work profile (Quality Assurance), teaching areas (Information Systems and Technology) and in specialization (Mathematics and Education). 